University of Wollongong

Research Online

Faculty of Social Sciences - Papers (Archive) Faculty of Arts, Social Sciences \& Humanities

2019

The material politics of smart building energy management: A view from Sydney's commercial office space

\author{
Pauline M. McGuirk \\ University of Wollongong, pmcguirk@uow.edu.au \\ Robyn Dowling \\ University of Sydney \\ Chantel A. Carr \\ University of Wollongong, ccarr@uow.edu.au
}

Follow this and additional works at: https://ro.uow.edu.au/sspapers

Part of the Education Commons, and the Social and Behavioral Sciences Commons

Research Online is the open access institutional repository for the University of Wollongong. For further information contact the UOW Library: research-pubs@uow.edu.au 


\title{
The material politics of smart building energy management: A view from Sydney's commercial office space
}

\author{
Abstract \\ The potential of cities in leveraging energy transformation is increasingly recognised, with a growing \\ focus on urban built environments. In this paper we focus on smart building energy management as an \\ increasingly pivotal material means through which energy transformation comes to matter in cities, and \\ through which buildings are politicised in the negotiation of energy transformation. We advance a \\ material political analysis of the case of Sydney's premium commercial office building sector to explore \\ how such buildings are conferred with political capacity. We explicitly extend this material politics \\ framework to pluralise the 'whereabouts' of the politics of energy transformation, expanding recognition \\ of the sites and moments of negotiation through which these politics are enacted, authority shaped, and \\ where trajectories of energy transformation begin to be fashioned. Drawing on this extended conception \\ of politics, the paper traces how the political capacity of buildings comes to matter through smart \\ building energy management platforms as they are negotiated through the context of Sydney's policy \\ settings, the political-economy of the top tier commercial office sector, and building management \\ cultures. We conclude with observations on how smart building energy management platforms might \\ contribute to the shaping of particular trajectories, possibilities and limits for energy transformation \\ advanced through the built environment.

\section{Disciplines} \\ Education | Social and Behavioral Sciences

\section{Publication Details} \\ McGuirk, P. M., Dowling, R. \& Carr, C. (2019). The material politics of smart building energy management: \\ A view from Sydney's commercial office space. Political Geography, 74 102034-1-102034-10.
}


The material politics of smart building energy management: a view from Sydney's commercial office space

McGuirk PM*, Dowling $\mathrm{R}^{\dagger}$, Carr $\mathrm{C}^{*}$

* Australian Centre for Culture, Environment, Society and Space, School of Geography and Sustainable Communities, University of Wollongong

${ }^{+}$School of Architecture, Planning and Design, University of Sydney

Paper published in Political Geography Volume 74, October 2019, 102034

https://doi.org/10.1016/j.polgeo.2019.102034

\begin{abstract}
The potential of cities in leveraging energy transformation is increasingly recognized, with a growing focus on urban built environments. In this paper we focus on smart building energy management as an increasingly pivotal material means through which energy transformation comes to matter in cities, and through which buildings are politicised in the negotiation of energy transformation. We advance a material political analysis of the case of Sydney's premium commercial office building sector to explore how such buildings are conferred with political capacity. We explicitly extend this material politics framework to pluralise the 'whereabouts' of the politics of energy transformation, expanding recognition of the sites and moments of negotiation through which these politics are enacted, authority shaped, and where trajectories of energy transformation begin to be fashioned. Drawing on this extended conception of politics, the paper traces how the political capacity of buildings comes to matter through smart building energy management platforms as they are negotiated through the context of Sydney's policy settings, the political-economy of the top tier commercial office sector, and building management cultures. We conclude with observations on how smart building energy management platforms might contribute to the shaping of particular trajectories, possibilities and limits for energy transformation advanced through the built environment.
\end{abstract}


The material politics of smart building energy management: a view from Sydney's commercial office space

\section{Introduction}

Securing a low carbon future is highly dependent on decarbonising the energy system. Globally this has proved a wicked problem', entangled in political, economic and technological challenges and embedded in obdurate institutional and material conditions. In this vexed context, the potential of cities to lead the way in assembling new energy systems and practices has come to the fore, with their material and political capacities proffering multiple opportunities to disrupt and reassemble energy infrastructure and demand (Haarstad, 2016, Webb et al. 2016). There is growing momentum around locally contingent, urban energy reconfigurations, including the urban built environment (see Jensen et al., 2016) and, the focus of this paper, diverse urban materialities such as grid/city intersections (Bulkeley et al. 2016a), and smart meters as mediators of urban energy practices (Strengers 2013, Bulkeley et al 2016b). In parallel, the urban built environment is increasingly targetted in policy and practice for the opportunities it offers for fostering energy transitions. In Australia, for example, where decarbonisation and transformation of energy remain caught in the throes of political indecision and infrastructural obduracy (Dowling et al. 2018), it has been suggested that buildings could address half of Australia's national energy productivity target and $25 \%$ of the national emissions target by 2030 (ASBEC 2016). Scholarly attention to urban buildings and energy transformations, in such journals as Building Research \& Information, Energy \& Buildings, Energy Policy, and Energy Research and Social Science, has focused on the intersections between building engineering, material construction and energy performance, along with attention to building occupant energy consumption and behaviour change. By and large, this scholarship considers the building in isolation from both its urban and political-economic context, and in so doing narrows recognition of possible roles for buildings in energy transformations. Thus in this paper we analyse buildings as connected to, and part of, urban energy transformations. In particular, we pay attention to the ways in which buildings are politicised as they are enrolled into these transformations, the material means through which this occurs, and what this might mean for their politics, possibilities and trajectories. 
The empirical focus of the paper is smart building energy management platforms ${ }^{1}$ which have emerged as key to how buildings are being located in political efforts to achieve urban energy transformation. Energy efficiency has been prioritised both in national energy policy regimes and across the building sustainability agenda, as transforming energy supply systems has proved challenging (Dowling et al 2018, Ruparathna et al 2016). Building environmental performance standards have become commonplace as pressure has grown internationally for the reconfiguration and repoliticisation of commercial offices, cast as problematically profligate energy consumers (Roberts and Edwards 2010, Faulconbridge et al 2018). Smart Building Energy Management (SBEM) is a critical response to these challenges. SBEM seeks to dynamically control (and reduce) building energy consumption via ubiquitous computing and advanced integrated data-analytical capacities focussed on dynamically choreographing and optimising building performance through adaptive, predictive and often automated management and control (Amin 2014, Buckman et al. 2014). It can also (theoretically) facilitate the integration of intermittent renewables into more sustainable energy supply systems (Rocha et al 2015).

In the Australian context that is the focus of this paper, SBEM has been promoted across the government and private sectors. The Australian Sustainable Built Environment Council (ASBEC) ${ }^{2}$ for example, promotes the capacities of such technologies-optimisation of building lighting, heating and cooling systems, fault detection, and the provision of real-time feedback to drive energy control-and their potential to reduce building energy consumption ${ }^{3}$ (ASBEC 2016). Likewise the real estate industry has embraced the 'long-range importance of a solid energy management system delivered via smart building technologies' as key both to sustainability and, crucially, to producing a price and yield premium on sustainable buildings (Herrenkolh 2017). The facilities management industry, meanwhile, is discussing the integrated technologies of SBEM as 'the new green' (Total Facilities 2017). Encouraged by technology corporates who have developed and promoted universal smart building platforms, SBEM has recently risen to the surface as most

\footnotetext{
1 Building Energy Management Systems (BEMS) are a well-established technology in the building engineering and facilities management industry. Smart building energy management (SBEM) is a newer concept that refers to the converging of conventional BEMS with ICT and data analytics capacity into platforms that enable the integration of multiple real-time data flows monitoring to allow for dynamic, often automated, adjustment of building performance (Rocha et al 2015).

${ }^{2}$ ASBEC is the peak body which represents industry and professional associations, non-government organisations and government in the building sustainability domain.

${ }^{3}$ Recognising the potential, global technology corporations-including Intel, IBM, Cisco, Siemens and Microsoft-have been at the forefront of nurturing the market for smart building management platforms. Talen and Goldstein (2015) have suggested that building energy management systems revenue for the office sector will grow from US\$979m in 2015 to US\$3.4m by 2024.
} 
likely to deliver energy efficiencies, energy productivity targets and decarbonisation (Thomas et al. 2015; ASBEC 2016). Not only are buildings pivotal in fostering and understanding urban energy transformation but SBEM platforms are emerging as a pivotal material means to achieve these transformations.

In this paper, we trace the contextual enrolment of buildings into energy transformation that, we argue, is configuring new constellations of actants around data-driven SBEM platforms that come to matter through multiple moments of politics that are contextually negotiated (see Rutherford 2014). We suggest that, as data-driven modes of SBEM become embedded, authorised and legitimised, they have the capacity to forge particular trajectories of energy transformation. However, this is predicated on how they come to matter-that is, how they are politicised and materialised - in place via material-political negotiation. Three key questions frame our analysis. First, how do commercial office buildings come to matter and attain political capacity in energy transformation through SBEM platforms in the Sydney context? Second, what forms of political negotiations are invoked around SBEM's technological material forms and how, in turn, do these negotiations further shape SBEM platforms' materialisation, authorisation and legitimation in place as a means for realising energy transformation? And, finally, how might the particular politicisation of Sydney's buildings, emerging around SBEM platforms and their material dynamics, shape the trajectories and possibilities for energy transformation?

These questions suggest material politics (Barry 2013, Minuchin 2013, Bulkeley et al. 2016b, Rutherford 2014) as a productive analytic through which to investigate how Sydney's commercial office buildings are conferred with political capacity in energy transformation, and with what effect. Crucially though, our analysis prompts us to extend work on material politics by to pluralising the understanding of the 'whereabouts' of politics in this formulation (Allen 2003, Bulkeley et al. 2016b, Bissell 2018). In particular, we seek to expand recognition of the sites and moments of negotiation in and through the politicization of buildings via SBEM platforms occurs, through which authority is shaped, and trajectories of energy transformation materialized. This suggests, following Rutherford $(2018,42)$ a contingent understanding of politics that appreciates that energy transformations evolve not on "passive or stable grounds on which politics takes place but are constituted by artefacts and relations, which then become fundamental to the conduct and possibilities of politics" (Rutherford 2018, 42). 
We begin by detailing the paper's theoretical framework, outlining the growing recognition of the political capacity of building materiality. We connect this to a material politics framework and detail our argument for extending the framework's recognition of sites and moments in which politics reside in socio-technical energy transformations in the city. Turning towards our empirics, we discuss methodology, before exploring the three framing questions for our analysis. We outline the emergence of SBEM platforms as a particular materialisation of buildings' political capacity in energy transformations, then turn to the specific material-politics through which this is being negotiated and comes to matter ${ }^{4}$ in Sydney. We conclude with observations on how the particular material politics emerging around buildings and SBEM platforms might shape trajectories of energy transformation.

\section{Developing a Material Politics Approach to Buildings}

Whereas buildings were once understood as "essentially standardised static objects" (Guy 2006, 653), geographic scholarship has moved progressively towards understanding them as complex and intertwined materialities and politics that are practised and dynamic rather than static (Edensor 2011, Jacobs and Merriman 2011, Beauregard 2015, Santos and Lane 2017). Moreover, buildings are themselves networks of many things: glass, steel, wood, lifts, electrical wiring, Heating-Ventilation-AirConditioning (HVAC) systems, Building Management Systems (BMS) (Jacobs et al. 2007). To this we would add the smart technologies and data analytic capacities combined in SBEM platforms (see Beauregard 2015). Thus, buildings are complex material infrastructures, composed of multiple elements and technologies that are intertwined with the energy, financial, technical, organisational and regulatory practices required to enable and maintain them. Sociotechnical scholarship on buildings, likewise, points to buildings as political/politicised entities that are "built in a process of social construction and negotiation" that embeds them in the shifting political, social and commercial interests of actors linked to their design and use (McKenzie and Wajcman 1985, Bijker and Law 1992: 13). They are practiced materialities that spur human and institutional responses, creating effects, stabilizing or disrupting social practices, networks, and institutions (Gieryn 2002; Kaika 2010, Beauregard 2015, Power 2015). Thus, buildings have come to be recognised not merely as "coherent, individual edifices that stand rather blankly, waiting to be used" (Kraftl 2010, 404) but their embeddedness in socio-political processes means that

\footnotetext{
${ }^{4}$ We deploy the term 'comes to matter' to designate both how the material dimensions of SBEM becomes political - that is, come to attention and become a point of negotiation and contention-and how the multiple sites of negotiation and contention, in turn, shape how SBEM materialises in particular contexts.
} 
"political negotiations and political contexts are woven together in the form and use of buildings" (Kraftl 2010,4024). Buildings, in other words, encompass political capacities.

Conceptions of buildings as political intersect productively with theories of material politics; a broad field informed by diverse theoretical affiliations (Minuchin 2013). A material politics approach seeks to establish how objects, devices, settings and materials acquire political capacities; that is, they shape how issues (such as energy transformation) are made meaningful in given contexts, and how, in turn, those political capacities are materialised and are contested (Hawkins 2009, Marres and Lezaun 2011, Barry 2013, Bissell 2018). Urban material political analyses have unpacked the particular socio-material entanglements that come to matter through site-specific contention and negotiation around issues as diverse as urban decarbonisation (Rutherford 2014), vehicle automation (Bissell 2018), access to urban sewerage services (McFarlane 2008); and smart energy transformations (Bulkeley et al. 2016a). In exploring how energy transformation is being made meaningful through the political capacities of commercial buildings, this analytic provides a framework through which to trace how these capacities are generated through SBEM platforms' material capabilities and, significantly, by how these platforms themselves are materialised in place as their enrolment is purposefully negotiated and contended, across Sydney's material, institutional and political contexts.

However, we argue that there is a need to extend on a material-politics framework by expanding on how the locus and mode of politics are understood. Some material politics accounts retain a focus on conflict, contestation or struggle as the mode of politics configuring how issues come to matter. This focus is limiting, failing to capture the wider diversity of the agents of potential political change and the wider diversity of sites and moments of politics. Following Bissell (2018) and Bulkeley et al. (2016b), we suggest that a conception of politics is needed that recognises multiple moments of negotiation, alignment or disruption wherein issues are shaped, actants enrolled for particular purposes, material relations (re)configured, and authority produced (see also Marres and Lezaun 2011). These are moments of politics not sufficiently captured by a conception of politics as expressed in conflict, resistance or strategic expressions of power. Things are politicised, then, not just in the sense of being controversial or contested, but also in the sense of being enrolled for particular purposes in particular contexts, (re)configured into particular alignments and thus made meaningful to particular groups and actors as they are put to work in place and granted authority (Rutherford 2018). A material politics approach, extended by this 
broader conception of politics, enables us to unpack how Sydney's commercial office buildings are conferred with political capacity in the process of urban energy transformation, and more specifically, how this comes to matter via SBEM platforms through multiple moments of recursive material-political negotiation.

These moments, we argue, arise particularly from the way building-integrated SBEM platforms fashion material trajectories of energy transformation around a particular material encounter with energy via data. SBEM platforms aim to render the building dynamically responsive and optimizable in real time by integrating ecosystems of computationally advanced, interoperable building systems into platforms fed by integrated data-feeds from multiple digital devicessensors, controls, apps-that instrument the building, connecting and orchestrating various building management capacities on air handling units, chillers, thermostats, electrical meters, lighting controls etc. (Intel Building Management Platform Product Brief, 2016). SBEMs' material assemblage promises to deliver a rich, granular data tapestry, linked to intelligent analytics capability and fused with control systems, data visualisations, data dashboards and other graphic user interfaces that "integrate isolated islands of information to extract new actionable insights" (IBM Smarter Building Management 2017). These platforms' integrated technological ecosystems find material expression in data streams, underpinned by a data-centric faith in the unhindered effectivity of data analytics, its calculative logics and assumed capacities to induce improvement by rendering building performance visible (see Kitchin 2016). However, a material-politics analytic, drawing on an extended understanding of the locus and mode of politics, suggests that the technological determinism inherent in this linear tech-data-optimisation vision glosses the material politics through which these SBEM platforms are politically negotiated, contended and come to matter in place (Rutherford 2014). Greater acknowledgment is warranted of how "technologies are not merely efficient devices or efficiency orientated practices, but include their contexts as these are embodied in design and social insertion (Feenberg 1999, xiii). We argue that the data-centric material encounter with energy afforded by SBEM platforms itself triggers politics - negotiation and contention-across multiple sites and moments whereby the way SBEMs come to matter in place is, recursively, (re)configured through intersections with particular purposes arising from Sydney's material, institutional and political contexts (see Gibbs and O'Neill 2015, Bulkeley et al. 2016a). In the analysis that follows, then, we focus on the geographicallysituated processes through which the material politics of SBEM take shapes circumstantially (see Bissell 2018), as SBEMs data-centric material expression encounters, must contend with and be 
negotiated through Sydney's energy policy settings, the political-economy of the commercial office sector and building management cultures.

\section{Methodology}

Researching the processes and practices of smart building management faces a number of constraints. Commercial-in-confidence claims limit access to building management practices and to the material stack of the proprietary software platforms associated with smart buildings (e.g. SBEM platforms' programming, software, data formats, and protocols etc). Thus, even though is it mandatory for buildings over $1,000 \mathrm{~m}^{2}$ to disclose of energy performance through the National Built Environment Rating Scheme (NABERS), access to information about how this performance is achieved remains a challenge. In order to overcome such constraints, a synthetic and adaptive mixed-method approach to collecting data for this paper was developed. First, a detailed review and analysis was undertaken of documentation available in the public domain across all media, including print, video and podcast. This included annual company reports, industry studies, government reports, and case studies conducted by professional and industry organisations. From this review we compiled a database of high-performing buildings in the CBDs of Sydney and Melbourne, which included the characteristics of smart energy management. This was supplemented further with 27 semi-structured qualitative interviews with key actors across the sector, including building owners, policy makers, building services consultants, facilities managers, and engineers. Together, document analysis, a database of building characteristics, and interviews, allow us analyse how energy transformation is being configured through buildings and SBEM platforms in the Sydney context. We begin by tracing how encounters with Australia's energy system and the local context of built environment energy governance has shaped the politicisation of the building and positioned SBEM platforms. Then we turn to the finer-grained negotiations and contentions that are induced by the materiality and material affordances of SBEMs and their data stream. We trace how these, in turn, craft how SBEM platforms and their material practice is realised materialised, become authorised and legitimated around particular purposes in the Sydney context as means through which energy transformation is to be advanced. We pay particular attention to how SBEM's technological material forms are negotiated. We take each of these sites and moments of negotiation to be a site of politics that, in turn, has the capacity to shape constraints and possibilities for energy transformation. 


\section{Politicising the commercial office building in place: negotiating the matter and meaning of}

\section{SBEM in Sydney, Australia}

A material politics analytic enables a questioning of how buildings are politicised via SBEM platforms, as well as a questioning of how SBEM platforms themselves are brought to attention and materialised via negotiations and contentions in place. In this section, we develop this analytic for SBEM in Sydney, we explicitly deploy the extended conception of politics outlined earlier in the paper, expanding our apprehension of the site and moments through which politics are enacted and political capacity is materialised in particular ways.

Sydney's commercial office buildings' positioning in energy transformation reflects Australia's wider energy politics. Australia has one of the world's largest centralised energy systems: the National Energy Market (NEM). The socio-technical obduracy of the NEM's highly complex and centralised material and institutional structure has stalled the largescale advance of energy system

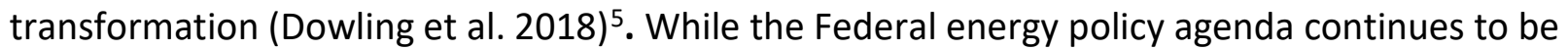
driven by logics of market competition and energy productivity rather than a more transformative clean energy agenda (Warren et al., 2016), the lower hanging fruit of pursuing energy efficiency and demand reduction still holds sway. NSW energy policy promotes renewable generation but is nonetheless largely confined to supporting the uptake of efficiency measures. Sydney's local energy objectives further reflect this context. While the City of Sydney (which governs Sydney's CBD) has been at the forefront of contesting the constraints that the national energy system present to facilitating building-level microgeneration capacity (see Dowling et.al.2018), the local energy policy context is still dominated by efforts to reconfigure energy demand through energy efficiency pathways, including promoting building energy efficiency often in partnership with the commercial office sector (see Dowling et al 2018, CoS 2015, ASBEC 2016).

National mandatory and voluntary building standards focused on building energy performance are especially important to built-environment energy governance ( $M \cong$ Guirk et al., 2014a, Dowling et al 2018). In this context, commercial office buildings have become the focus of conscious negotiation in the politics of energy transformation on the basis of claims to potentially contribute significantly to redressing 'energy crisis' $^{6}$, via an estimated total energy reduction potential of at least

\footnotetext{
5 The pathway to such transformation is unclear and intensely politically controversial. The latest attempt to reform the national energy system collapsed with the resignation of Australia's Prime Minister in August 2018.

${ }^{6}$ As energy shortages and blackouts struck in the summer of 2016/17, the Australian PM publicly described an impending 'energy crisis'.
} 
5,142GWh by 2020 (ASBEC 2016). Reconfiguring energy through commercial buildings is being pursued through multiple means that align multiple actors and materialities including policy instruments, property corporations, (often financialised) performance metrics, and, crucially, SBEM platforms (Carr et al 2018). A suite of federal, state and local policy instruments now coheres around commercial office space (Table 1) and has helped constitute global recognition of the energy and wider sustainability performance of the top tier buildings in Sydney and Melbourne. This top tier is concentrated in Sydney's CBD, with over 5 million $\mathrm{m}^{2}$ of commercial office space and constitutes half of the CBD building stock (PCA 2018). The focus on building energy performance is intense in this sector and sites. For instance, the Better Buildings Partnership, a voluntary initiative that incorporates approximately half of Sydney's core CBD properties, has saved $\$ 33 \mathrm{~m}$ p.a. in electricity costs while achieving a 52 per cent reduction in emissions (Fifth Estate 2018a). The NABERS 7 energy performance rating has proved particularly catalytic: by law (the Commercial Building Disclosure Act), the rating has to be disclosed on sale or lease of commercial offices spaces. NABERS has become a way of knowing a building and a proxy for the material quality of office space, argued to be "capable of motivating all supply-side players and moving the market" (Bannister 2017). Reflecting the international targeting of the high energy-consuming office building sector for energy efficiencies (Economidou 2012, Knuth 2015), the highly competitive top end of the commercial office space market is increasingly positioned within metricised, financialised building performance and green investment ratings schemes that target built environment materiality, such as the $\mathrm{GRESB}^{8}$. As metricised forms of calculation, these are informing top tier property corporations' portfolio management strategies, guiding property investment strategy, and shaping competition for quality tenants (see Devine 2017 for international evidence). Thus, the political economy of the top end of the sector alongside a relatively effective suite of governance mechanisms have positioned Sydney's premium and Agrade commercial buildings as global best practice and as political agents in the fashioning of pathways to energy transformations (ASBEC 2016; Bannister 2017).

\section{TABLE 1 HERE}

\footnotetext{
${ }^{7}$ NABERS is the National Australian Built Environment Rating System.

${ }^{8}$ GRESB - the Global Real Estate Sustainability Benchmark -is an investor-driven benchmark for assessing the sustainability performance of real estate sector portfolios and assets. In 2018, GRESB provided assessments for 1283 real estate funds, property companies, infrastructure assets and debt portfolios.
} 
More crucial to our analysis, however, is that the impetus to materialise energy performance via NABERS and international investment ratings creates markets for, legitimises and produces authority for SBEM platforms as effective means of both enhancing and demonstrating energy performance. Yet this is not rolled out in the abstract, it is enacted and attains meaning in place, through multiple moments of negotiations that, in turn, affect the specific material constitution and practice of SBEM. In exploring this, we focus on two domains of negotiation. The first arises from the claims to authority around the material-technological capacities of SBEM platforms to enhance energy management via data analytics and data visualisation, thus disrupting settled relations between building owners and building management firms. The second arises from negotiating the practices and capacities embedded in building management cultures and how this shapes SBEM's specific materialities and material practice in the Sydney context.

\subsection{Materiality and contesting authority in Sydney's building performance management}

SBEM platforms' material-technical capacities for manifold sensing and data analytics make the inner workings of a building visible in ways not attainable through conventional Building Management Systems (BMS). They materialize a building's energy consumption in the form of integrated data flows, sourced from multiple sensors (on lighting, energy, humidity, temperature metres, building utilities, appliances, water systems, heating and cooling systems etc), and analysed into diagnostic and predictive analytic data outputs which render that consumption visible, recordable and thus governable and manageable (echoing the calculative systems behind carbon accounting, Rice 2010). SBEM platforms' material outputs-integrated data analytics that track, diagnose, and predict patterns of building environmental performance-are said to provide the capacity to "really see" the building's dynamic performance in real time. As IBM's Smart Building Management brochure says of SBEM platform's data visualisation: "This dramatic change in visibility is like viewing the night sky with a powerful telescope instead of just looking up at the stars with the naked eye... reveals a completely different understanding of how buildings are working-or not working-with new awareness into the origins of issues and problems, enabling new knowledge that leads to improved operational methods". As SBEM platforms' integrated technological ecosystems find material expression in building-specific data streams, dashboards, and a host of additional data materialities available across various commercial products (data benchmarking, data alert systems), SBEM platforms output actionable information to guide building management, whereby building managers "can easily optimise [their] facility's energy and 
operational efficiency, allowing [them] to increase productivity and enhance decision-making" (http://corporate.siemens.com.au/en/home/our-businesses/building-technologies/buildingmanagement-systems/desigo-cc.html).

Materialising and visibilising building energy consumption as data provides new and enhanced capabilities for demonstrating particular buildings' energy performance credentials. These are able to inform wider established ratings systems both in environmental performance (such as NABERS) and international ratings and metricised investment systems, which in turn inform investment markets and financialise building performance (such as GRESB-the Global Real Estate Sustainability Benchmark). As one interviewee, a Director of Sustainability for a large engineering consultancy, put it:

(Top tier building owners) want to be able to demonstrate that their buildings are achieving best practice, whatever that means...(for) example, the GRESB, they're all competing against each other. So (for) the portfolios, there's nowhere to hide. They've got to be in it to actually demonstrate they're part of the game if you like. ...So it's that competition that occurs in that space...

Along similar lines, the Director of a prominent Industry organisation noted that other kinds of instruments for financialising building asset value, such as climate bonds, are also dependent on the ability of data to demonstrate performance. In this context, all top tier building owners 'want to be able to demonstrate that their buildings are achieving best practice' (Director of Sustainability, Engineering Consultancy). SBEM platform data outputs are effective in part because, as one interviewee put it, "everyone can touch it and feel it and there's tangible benefits that you can demonstrate". SBEM platforms' political agency, then, arises substantively from this materialisation of energy consumption in which data outputs are put to work by particular actors and interests. Building owners, operators and investors are motivated to configure and capitalise on these platforms to produce optimal performance efficiencies (in terms of environmental performance and costs), alongside the enhanced investment yields such performance can underwrite, while also meeting growing legal and social obligations around environmental performance (Knuth 2015, Talen and Goldstein 2015). SBEM platforms thus attain political capacity as actants in "the practice of changing the rules of practice" (Dünckmann and Fladvad 2016, 25). 
Not only do SBEM platforms attain political agency through the affordances of their material capacities, but their political significance and meaning is also to be found in how these capacities are reworking the relations of building ownership and building management. SBEM platforms operate as computational ecosystems, designed to sense multiple data flows and use open data protocols to extract data from BMS, drawing across traditionally-siloed building infrastructure systems, to produce integrated data analytic outputs that extend the transparency of building data. Top-tier buildings employ increasingly sophisticated intelligent BMS as a matter of course, many of these provided by long-established and widely engaged international BMS firms (eg Honeywell, Schneider, Johnsons). However, these are often limited by proprietary coding and closed protocols that limit the exportation of data into other analytics platforms with data-integration capabilities. Until recently, BMS companies have predominantly been monopoly providers that connect BMS, building services and maintenance contracts and tie building owners into long term contract arrangements. However, building owners' and investors' interactions with SBEM platforms instigate questioning of this status quo. Interviewees characterised the scene as follows: BMS companies are stuck in the 1980s... Closed protocols, and that's - look, it's not the protocols so much. It's just their nature to capture a building, keep a building, lock people in, and they're just not being innovative, not being interested in having a conversation with their customers about what they really want...

(Sustainability Manager, large portfolio owner)

We're starting to specify open protocol BMS systems that are used in the development framework... Hopefully then we can start to bring a lot more data together but it's hard. Even now everything's siloed... but I think once we've got them onto a converged network I think that's when we'll start to really get the benefits of big data. I do think there's huge benefits there. I think at the moment though we are literally scratching the surface.

(Sustainability Manager, large portfolio owner)

...opening up that data set and making sure those protocols are open and non-proprietary and can be read by third party systems is something that we and all owners want to happen but is a slow thing to shift. It's a fairly entrenched set of offerings in the market, but we're seeing really great evolution in that space.

(Sustainability Manager, large portfolio owner). 
Smart building energy platforms become part of the negotiation of 'changing the rules of practice'. SBEM platform firms vary in purpose and capability (and thus, cost) and provide varying packages of smart energy data monitoring, integrated data analytics information, 'actionable insights' and pre-emptive alerts, through to machine learning capability and the extensive automation of building energy management (see Table 2). Crucially, their material technologies-including open data protocols that sit across and connect conventional BMS-are disrupting conventional social orderings, material relations and building management practices and shaping new relations of authority in which SBEM platforms can inform the possibility and limits of energy transformation through the built environment. The process was described thus by one Sustainability and Property Manager for a large portfolio owner:

the Switch Automations, Envizis, Buildings Alives, have moved into that space... and the benefits of those guys (is that) they're technology agnostic. ...Because we have multiple buildings, and because those buildings are effectively locked into (a BMS system), if we want to have the same approach across all buildings, then we've got to put a different, independent layer over it so that, as building owners and managers, we can say to all our operations managers, here's the way we manage energy in our buildings, and it's not beholden to what Schneider out of Europe or Honeywell out of US thinks is the right thing to do.

SBEM platforms' material capacities trigger political contention in the world of commercial office building management, unpicking the immanent authority of existing ways of doing things (Bulkeley et al. 2016a), reconfiguring the building management industry and becoming part of an emergent political-economic interest coalition aligned to the purpose of reconfiguring building energy management around smart building technologies/ data analytics (see Rutherford 2018).

\section{TABLE 2 HERE}

SBEM platforms attain authority and legitimacy through their material capacity to mobilise, integrate and visualise building energy data. This material-political capacity in turn repositions the building and building energy. It makes buildings' energy performance present, visible and knowable in new ways (integrated data visualisations, integrated dashboards etc). In problematizing building energy performance, these technologies create affordances for it to be 
ordered in new ways, suggesting changed energy management practices or indeed building upgrades that, in allowing building owners to meet legislative and social obligations, can become authoritative (see Hawkins 2009). Significantly, they are reworking the relations of authority and order that has characterised the political economy of building management. To paraphrase Marres and Lezaun $(2011,495)$, SBEM platforms - through their material capacities to integrate data, produce data analytic outputs that make energy consumption visible and governable-thus gain a political capacity to mediate matters of concern, throwing issues into debate, reworking existing socio-material practices, reworking material relations, disempowering some and authorising others. They gain an agentic capacity to make a difference to how energy transformation comes to matter, expressed and mobilised through the particular circumstances and political economy of Sydney's top tier commercial office buildings (see Bissell 2018).

\subsection{Negotiating building management cultures in the materialisation of SBEMs in Sydney}

In this section we draw specifically on an expanded conception of politics to capture the multiple sites of politics - of negotiation and contention-that recursively shape how SBEM attains meaning and comes to matter in place. These material-political negotiations mediate the contending futures of building energy management, and thus of energy transformation, in Sydney. We attend to three key moments in what follows. A first key moment of negotiation involves the tradeoffs between SBEM platforms' material outputs and the sector's capacity to absorb and work effectively with these. How SBEM platforms are realized and deployed within the sector is fundamentally shaped by how these tradeoffs are negotiated and settled. SBEM platforms output vast flows of data analytics, but the transformative capacity of these data outputs to 'change the rules of practice' around building energy management must be worked through in the existing conditions of building management practices and its on-the-ground capacities ${ }^{9}$. This working through is a moment in which the political capacity of SBEM platforms in mobilising energy management (and indeed that of buildings themselves) is made to matter in particular ways.

In the Sydney context, building management professionals and building owners generally found that "the data story is going to be too complex" (Technical Director, engineering firm), "people (are) talking about smart buildings and they're talking about 'smart technology' and they're talking about 'data science' and 'big data', and all of that sort of stuff can easily get confused. Like 180

\footnotetext{
${ }^{9}$ This reflects Plantin et al's (2018) emphasis of the importance of attending to how such platforms and infrastructure are co-constituted by work practices and organisational culture.
} 
degrees confused" (CEO, building analytics firm). Indeed, many remained mystified by its potential. One interviewee wryly quipped that "data analytics is a bit like teenage sex. Everyone's talking about it but no one really knows what it is" (Manager, building services consultancy firm). Additionally, the scope of these technologies' ubiquitous monitoring-the sheer volume of their material output-means that the capacity of building managers is quickly saturated. One interviewee, the CEO of a building analytics firm, explained:

you can peel back layers and go underneath that if you wanted to and look at systems like air handlers or chillers and look at all the points around the pressures and temperatures...and look at how they interact. That level of analytics, you're getting diminishing returns. It definitely can be helpful but you're getting diminishing returns...So I can see with all these technologies coming, it becomes more and more overwhelming for people ... the analytics throwing up flags, thousands of them a day, that's not very smart either. So these guys don't have any time....

Another characterised the mismatch between data analytics capacity and the realities of building management:

I'll walk into a building and there may be 1000 issues... Analytics, set up properly, will know what the 1000 issues are...The flip side of that is it produces all of this information someone's still got to work their way through and work out what's important and what's not important and how much of that information actually is going to - would send you off in the wrong direction for a long time, when it's not worth pursuing at this point....

(Sustainability Manager, engineering consultancy)

These platforms' materialisation in Sydney is shaped by the fact that, as one interviewee put it, "we still haven't broken the back of getting the right information to the right people at the right time, and allowing them to act on it, and allowing them to know what to do in response to that" (Sustainability and Property Manager, large portfolio owner).

SBEM platform's imputed material-political capacity to transform the rules of practice must, then, be negotiated contextually, and these negotiations in turn condition material practice. Responding to the complexity of SBEM platforms' material outputs, one prominent firm that supplies smart solutions for energy management to dozens of commercial buildings across Sydney's CBD, has developed a service that is distinctly different from the complex, multi-component smart ecosystems and ubiquitous data flows of the tech corporate visions. Addressing Sydney's context, the firm's founder argued that efficient energy performance does not require "expensive 
technology...or... a fancy efficiency-improving software suite" (CEO, building analytics firm). Rather, negotiating both the uncertainties of Sydney's policy context ${ }^{10}$ and the limited capacity of building managers to engage with complex data analytics, his firm works with a low-cost digital artefact that operates to "interfac(e) with complex building systems to extract data and then turn that data into highly refined information and analysis" (firm website), providing a smart building solution that operates for "a few cents per square metre" (CEO, building analytics firm), requiring minimal capital equipment.

A second, related moment of negotiation involves how SBEM platforms' capacity for building automation engenders resistance from both building management professionals and buildings owners, skeptical about the potential for building automation embedded in SBEMs materialtechnical capacities. Again, how these negotiations are resolved shaped how SBEM platforms specific materiality and meaning is shaped, the place they take in shaping building energy performance and the trajectories of energy transformations associated with the building. Many we interviewed recognised buildings as dynamic rather than static or stationary objects and as responsive material agents rather than entities with fixed fundamental performance attributes. Thus, managing building energy performance was taken to require more than technology but a working (human) expertise and knowledge of the material uniqueness of each building and its performance. As one interviewee put it:

buildings are not as sophisticated as what people think and those controls and those sensors and all the devices that are generating this data are not necessarily hugely reliable in the same way buildings work is not as predictable as you might think. So I think we're a little way away from the self-driving building. So in the meantime, we probably want betterinformed humans driving them. (CEO, building analytics firm)

Thus, while SBEM's have the material-political capacity to mobilise integrated data analytics to drive automated building management systems, more commonly found in Sydney are SBEM platform services that work in concert with building/facilities managers working responsively and adaptively with customized data feeds and alerts. For example, one market-leading firm has developed an explicitly socio-technical approach, side-stepping the data-centric, algorithmic capacities of SBEM platforms. Rather its SBEM merges data science and visualization with

\footnotetext{
${ }^{10}$ Firms' willingness to invest in energy efficiency is inflected by ongoing uncertainties around whether Australian energy policy will continue to prioritise energy efficiency over renewable generation.
} 
individualized building management techniques. It gathers data from building management systems and energy meters and combines it with historical weather data to come up with a building-specific equation that compares predicted with actual use on a daily basis. Buildingspecific data are provided to the building operator via a daily email message that enables them to fine-tune the buildings' systems in near real-time, while providing hands-on building engineering advice. Thus this SBEM platform firm combines technological aspects with a "people-based service", that emphasises "...the ghost in the machine: the real people who continually optimise each building's systems to deliver real, measurable improvements" (FM Magazine 2012). This combination of data analytics and human engagement enables it to "make sense of a specific building (italics added)" to provide customized energy optimization programs. As the firm's website states: "We endeavour to learn and understand each building we work with and then help the operators achieve results on a peer-to-peer basis by supporting, coaching, assisting". Their approach reflects wider recognition across the sector that:

You just have to figure out each building case by case because they're all different and they will have their own particular quirks and design features and flaws...knowledge of the building is crucial (Sustainability Manager, large portfolio owner).

Deriving each building's smart energy management strategy thus becomes a site of politics; another moment of negotiating the frictions around how the material capacities of the technology, the material character of the building and its biophysical context, and the knowledge of building owners and managers can be aligned. This alignment must also contend with the calculative demands of the policy context that requires specific forms of demonstrable energy performance from commercial buildings. Through these negotiations smart building energy management, and indeed the building as a site of energy transformation, comes to matter in particular ways that are elaborated contextually.

A third site of negotiation relates to the capacity of building facilities management firms to work with SBEM platforms' material outputs. Sydney's commercial office sector's facilities management (FM) industry is widely acknowledged to be challenged by a lack of expertise, capability and capacity around smart building energy management ${ }^{11}$ (Fifth Estate 2018c). As one SBEM firm

\footnotetext{
11 One indication of recognition of the skills and capacities gap is the fact that recent Total Facilities industry conferences in Sydney have featured a 'Smart hub' or 'Smart Zone' presenting technological innovation and 'new technologies and solutions to help create smarter, greener buildings'. These are aimed to provide strategic advice to upgrade FM capacity to understand and manage buildings via technology and data (Fifth Estate 2018c)
} 
website put it, "we understand that building operators often do not have the necessary tools, information, technical know-how and time to achieve optimum performance". Lags in training and knowledge around SBEM platforms and their material outputs are coupled with the nature of contract conditions that limit the time FM staff have to dedicate to responsively fine-tuning buildings. This invokes a significant tension or friction between the material technological capacities of SBEM platforms and the realities of on-the ground FM skills and capacities. One interviewee, recounting an exchange with an FM firm, characterised the tension:

we were talking about ... cutting edge smart buildings, and he goes, "that's all very nice guys, but my (FM technicians) that get sent by their bosses as apprentices, they've got no idea about that shit... they see one of those fancy things on the wall, chances are they're going to rip it off and put something on that they know". And you just go, "smart buildings"? (Manager, industry organisation)

Another highlighted the problem of accessing staff with the capability to engage with SBEM platforms:

What I do know though..is that it's not-I can't go out and employ people with those skills easily. They're very hard to find. (Sustainability Manager, engineering consultancy)

Others noted the contention caused by the way normalised building management practices and FM contract systems have an immanent authority that, in a socio-material sense, resists the technologies' integration (see Bulkeley et al. 2016b):

(there's) limited opportunity for them to develop skills through their work and pressure to stretch them as far as possible and I see contracts negotiated where they have no time. So they're very, very thin on the ground. They don't have much time. (CEO, building analytics firm)

(In one instance a SBEM platform firm) put the analytics on the building and it produced a massive volume of issues. (It) totally overwhelmed the clients...none of the service providers they had would sift through that and actually say "that's important, that's important". So they went "right, we're going to end that project". (Manager, Sustainability engineering consultancy)

Yet there are ways in which these platforms' output can be developed to align with FM skill-sets that smooth out these tensions, overcome the frictions, and make acting in line with the technological capacity doable, and more likely to become authoritative (Bulkeley et al. 2016b). As 
one interviewee, the Sustainability and Property Manager of a large portfolio owner, put it:

But if you can turn (complex data flows on building energy use) into a daily

profile...compared to the ideal daily profile, and show that to a technician. It takes training to allow them to interpret that picture [but] once they interpret the picture they say "oh, yeah, so (a building system) stayed on last night, so that was the problem".

How these contentions are negotiated are suggested by one firm's approach. Eschewing more technologically sophisticated smart modalities, "human-to-human engagement" and social learning are central to the firm's approach to the technology platform they offer. The service they offer combines smart data analytics with peer-to-peer dialogue and collaborative learning in a community of practice. They describe their approach as "very much focused on people to people relationships", geared at having building managers share knowledge "...to ensure people are comfortable with the strategies before taking them on a journey to optimise a building" (Fifth Estate 2016). Clients have to agree to be transparent about their building's performance, and the firm manages an online social network through which clients regularly swap ideas about their data, how they adapt building energy management in response, and how their building responds to FM fine-tuning.

The material context of deficits in smart FM expertise in Sydney, and the variability of expertise across individual buildings, also accounts for the way this firm customizes a data analytics and building management package for each individual building. So rather than promoting investment in new smart energy infrastructure in a building, this firm seeks first to enhance FM skills to get more out of existing plant by skilling-up building operators. The vision is not one of managing energy via smart building automation, but one of:

still having the human being but more at a higher-level function where they evaluate: this anomaly's been identified-you wouldn't see it if it wasn't for...the massive computations that have just happened and have found that it probably stands out as unusual for some reason. Then you get someone really experienced and capable to look at that and see why that might be...and then take it and then hand it to someone to do something. (CEO, building analytics firm)

This particular socio-materialisation of an SBEM platform, negotiated in the context of Sydney's FM industry, reconfigures material relations in part by rewiring human networks. The wider point however, is that the material politics of SBEM platforms not only involves these platforms 
attaining political capacity in shaping building energy management but that how these platforms attain meaning and come to matter is itself subject to multiple moments of negotiation and contention in place. Thus understanding the intersection of materiality and related negotiations and contentions becomes key to understanding how SBEM, its material practice, limits and possibilities unfold. And there are implications here for how trajectories of wider energy transformation come to be.

\section{Conclusion}

This paper suggests how energy transformations are being made meaningful through the material political capacities of commercial office buildings. We have illustrated how buildings' political capacities are shaped by the materialities of SBEM and how they shape building energy management, mediated by multiple sites and moments of negotiations across Sydney's policy settings, the political-economy of top tier commercial office buildings, and the city's building management cultures. Our material political account not only attends to the political capacity of buildings and building technologies but, in developing an expanded apprehension of politics, takes seriously the plural sites and moments of negotiation involved in SBEM platforms' material integration into energy transformation. Like energy transformation itself, incorporating smart building energy management is co-produced through the negotiation of institutional arrangements, technologies, materialities, social practices and actor constellations (see Rohracher and Späth 2013). These are the politics through which through which SBEM platforms come to matter in place. A broader implication is that energy transformation is not guided by a transcendent site of political control (Bissell 2018) but, rather, will be leveraged through an ecology of interventions and actions negotiated across an array of sites and moments through which new relations, interests, practices and materialities can be authorised and normalised. This perspective opens up new, productive lines of thinking about the opportunities of governing environmental transformations through building materialities (see Power 2015), while recognising that such governance will not be technologically determined but will be the product of contexualised material politics.

In concluding, we wish to offer some informed reflections on how the specific politicisation of buildings emerging around SBEM platforms in Sydney outlined above may shape trajectories and possibilities of energy transformation. Given the processes of negotiation in place that this paper has foregrounded there is, necessarily, an element of the speculative to these reflections. We can 
however make two relevant observations. First, energy transformation possibilities are being reshaped by the particular (data-driven) material encounters with energy enacted by SBEM platforms. For instance, new modes of calculation that authorise (local and global) building sustainability ratings systems, such as GRESB, are being legitimised. Emergent reconfigurations of building management culture and facilities management training are gaining traction through materialised data. They prioritise and configure new actor constellations around data-driven modes of energy management related to particular kinds of technological responses. They are disrupting settled relations between building owners and building management firms and suggesting emergent directions for reconfiguration in the building management industry. In so doing, they solidify trajectories of energy transformation focussed on logics of building optimisation rather than on dramatically restructuring modes of energy generation toward decentralisation and decarbonisation, nor challenging energy intensive social practices. This raises further questions around what Plantin et al (2018) have termed the simultaneous 'platformisation of infrastructure' and the 'infrastructuralisation of platforms', as SBEM platforms become more central to the functioning of commercial office buildings and their environmental performance. As SBEM becomes an essential part of a building's functionality (ie becomes infrastructural), it is increasingly 'platformised': that is, connected via ecologies of programmable data-capturing devices. However, unlike other forms of public urban infrastructure, platformed infrastructures are uniquely privately owned and controlled, and substantively wedded to an economic, profitoriented logic. We are yet to fully apprehend how this might inflect energy transformation futures.

A second observation relates to the way in which energy transformation trajectories will be shaped by the settlements reached, across multiple sites and moments of politics, as SBEM platforms are enacted. It is here that our extension and pluralisation of material political analyses' conception of the 'whereabouts' of politics comes to the fore. Our account of the material politics of SBEM platforms' roll out in Sydney's commercial office buildings suggests three key sets of intersections where these politics surface in ways that are not fully recognised by a conception of politics focussed on conflict, contestation or struggle. First is the intersection between competitive political-economic interests as currently arrayed in top-tier commercial office space building management regimes and the ways these arrays are being unsettled by performance standards and financialised indices (NABER/GRESB) that are reconfiguring environmental and market expectations for building performance. Second is the intersection between the authority conferred on and assumed by data analytics and the on-the-ground capacities (for instance among 
facilities managers) to work with them. This should, in turn, draw our attention to the fine-grain sites of negotiation, for example around FM contract conditions, that reflect and condition building management norms in the city and how they come into contact with and mediate the materialities of smart energy technologies. Third is the intersection between the linear, technologically-determinist 'automate/control' imaginary of many SBEM platforms, on the one hand, and building managers' recognition of buildings' lively and unique socio-materiality on the other. This raises the broader question of understanding building management as a sociotechnical interface and thus a site of politics. It is across these intersections - understood as moments of politics - that buildings' political capacities to shape energy transformation will be realised. The politics of how trajectories of energy transformations are realised is not only plural but irreducibly contextual.

\section{Acknowledgements}

This work has been supported by the Australian Research Council via ARCDP150100991. There are no conflicts of interest to report. Thanks are due to the editor and reviewers for their careful and productive engagements with the paper and their constructive critiques. The paper has undoubtedly been refined by their contributions.

\section{REFERENCES}

Allen, J. (2003). Lost Geographies of Power. London: Wiley. Amin, A. (2014). Lively infrastructure. Theory, Culture and Society, 31, 137-161.

ASBEC (2016). Low Carbon High Performance: How Buildings can Make a Major Contribution to Australia's Emissions and Productivity Goals. Australian Sustainable Built Environment Council. Available at:

https://climateworks.com.au/sites/default/files/documents/publications/summary_report__low_carbon_high_performance_20160511_1.pdf

Bannister, P. (2017). Why is Australia better than the UK at building energy efficiency? Energy

Management, January, 18-20.

Barry, A. (2013). Material Politics. West Sussex: Wiley-Blackwell

Beauregard, R. (2015). We blame the building! The architecture of distributed responsibility. International Journal of Urban and Regional, 39, 533-549.

Bijker, W.E. and Law, J. (1992) (Eds) Shaping Technology/Building Society. Cambridge, M: MIT Press.

Bissell, D. (2018). Automation interrupted: How autonomous vehicle accidents transform the material politics of automation. Political Geography, 65, 57-66.

Bulkeley, H., M`Guirk, P.M., Dowling R. (2016a) Making a Smart City for the Smart Grid? The urban material politics of actualising smart electricity networks. Environment and Planning A, 48, 17091726

Bulkeley, H., Powells, G. and Bell, S. (2016b). Smart grids and the constitution of solar electricity conduct. Environment and Planning A, 48, 7-23. 
Buckman, A.H., Mayfield Stephen, M. and Beck, B.M. (2014). What is a Smart Building? Smart and Sustainable Built Environment. 3, $92-109$.

Carr, C., M`Guirk, P.M., Dowling, R. (2018) Geographies of energy transition: the case of high performing commercial office space in the CBDs of Sydney and Melbourne, Australia. Australian Geographer https://doi.org/10.1080/00049182.2018.1536319

City of Sydney (2015) Energy Efficiency Master Plan 2015-2030. City for Sydney. https://www.cityofsydney.nsw.gov.au/_data/assets/pdf_file/0020/241436/Energy-EfficiencyMaster-Plan-low-res.pdf

Devine, A., Steiner, E. and Yönder, E. (2017). Decomposing the Value Effects of Sustainable Investment: International Evidence (February 20). Available at SSRN: https://ssrn.com/abstract=2920788 or http://dx.doi.org/10.2139/ssrn.2920788

Dowling, R., MGuirk, P.M., and Malleson, S. (2018). Governing energy transitions: exploring the role of the urban in multilevel governance. Energy Research and Social Science, 44, 260-67.

Dünckmann, F. and Fladvad, B. (2016) The practice of changing the rules of practice: an agonistic view on food Sovereignty. Geographische Zeitschrift, 104(1), 25-49.

Economidou, M. (2012). Energy performance requirements for buildings in Europe. REHVA Journal, March, http://www.rehva.eu/fileadmin/hvac-dictio/ 03-2012/energy-performancerequirements-for-buildings-ineurope. pdf

Edensor, T. (2011). Entangled agencies, material networks and repair in a building assemblage: the mutable stone of St Anne's Church, Manchester. Transactions of the Institute of British Geographers, 36 238-252.

Faulconbridge, J., Cass, N., and Connaughton, J. (2018) How market standards affect building design: The case of low energy design in commercial offices. Environment and Planning A, 50, 627-650.

Feenberg, A. (1999). Questioning Technology, London: Routledge .

Fifth Estate (2016). Buildings Alive and Envizi team up. August 30, https://www.thefifthestate.com.au/investment-deals/buildings-alive-and-envizi-team-up

Fifth Estate (2018a). Better Building Partnership looks set to smash emissions targets. March 26, https://www.thefifthestate.com.au/innovation/facilities-management/the-trends-changing-theface-of-facilities-management.

Fifth Estate (2018b). The changing face of facilities management and the three game-changing trends. March, https://www.thefifthestate.com.au/columns/spinifex/the-changing-face-offacilities-management-and-the-3-game-changing-trends.

Fifth Estate (2018c) The trends changing the face of building management. March 19, https://www.thefifthestate.com.au/innovation/facilities-management/the-trends-changing-theface-of-facilities-management.

FM Magazine (2012) Live-to-web data feed reveals energy savings. 20 March, https://www.fmmagazine.com.au/live-to-web-data-reveals-energy-savings/.

Gibbs, D. and O'Neill, K. (2015). Building a green economy? Sustainability transitions in the UK building sector. Geoforum, 59, 133-141.

Gieryn, T.F. (2002). What buildings do, Theory and Society, 31, 35-74.

Guy, S. (2006). Designing urban knowledge: competing perspectives on energy and buildings. Environment and Planning C, 24, 645-659.

Haarstad, H. (2016). Where are energy transitions being governed? Conceptualizing the complex governance arrangements for low-carbon mobility in Europe. Cities 54, 4-10.

Hawkins, G. (2009). The politics of bottle water. Journal of Cultural Economy, 2 189-95.

Herrenkohl, J. 2017) Smart Buildings: Why Energy Management Matters. https://www.ey.com/en gl/real-estate-hospitality-construction/smart-buildings-why-energymanagement-matters. 
Intel Building Management Platform Product Brief (2016) Available at:

https://www.intel.com/content/www/us/en/smart-buildings/building-managementplatform/bmp-product-brief.html

IBM Smarter Building Management (2017) Available at: https://www-

935.ibm.com/industries/govenrment/smart-building-management-paper/\#/benefits-of-utilizingdata-insights-allocating-space-for-improved-efficiency. Accessed 3/8/2017

Jacobs, J.M., Cairns, S. and Strebel, I. (2007). A tall story...but, a fact just the same': The Red Road high-rise as a black box. Urban Studies, 44(3), 609-629.

Jacobs, J.M. and Merriman, P. (2011) Practising architectures. Social \& Cultural Geography, 12, 211-222.

Jensen, J.S., Fratini, C.S. and Cashmore, M.A. (2016). Socio-technical systems as place-specific matters of concern: the role of urban governance in the transition of the wastewater system in Denmark. Journal of Environmental Policy \& Planning, 18, 234-252.

Kaika, M. (2010). Architecture and crisis: re-inventing the icon, re-imag(in)ing London and rebranding the City. Transactions of the Institute of British Geographers 35, 453-474.

Kitchin, R. (2016). The ethics of smart cities and urban science. Phil. Trans. R. Soc. A 374 : 20160115.

Kitchin, R. (2017). Thinking critically about and research algorithms. Information, Communication and Society., 20, 14-29.

Knuth, S. (2015). Seeing green in San Francisco: City as resource frontier. Antipode, 48, 626-644.

Kraftl, P. (2010). Geographies of architecture: the multiple lives of buildings. Geography Compass 4, 402-415.

Marres, N. and Lezaun, J. (2011). Materials and devices of the public: an Introduction. Economy and Society, 40, 489-509.

McFarlane, C. (2008). Political infrastructures: governing and experiencing the fabric of the city. International Journal of Urban and Regional Research, 32, 363-374.

M`Guirk, P.M., Dowling, R. and Bulkeley, H. (2014), Repositioning urban governments? Energy efficiency and Australia's changing climate and energy governance regimes, Urban Studies, 51, 2717-2734.

McKenzie, D. and Wajcman, J. (1985). The Social Shaping of Technology. Milton Keynes, Bucks: Open University Press.

Minuchin, L. (2013). Material Politics: Concrete Imaginations and the Architectural Definition of Urban Life in Le Corbusier's Master Plan for Buenos Aires, International Journal of Urban and Regional, 37, 238-258.

Power, E. (2015) Placing community self-governance: building materialities, nuisance noise and neighbouring in self-governing communities, Urban Studies, 52, 245-60

Plantin, JC, Lagoze, C., Edwards, P., and Sandvig, C. (2018) Infrastructure studies meet platform studies in the age of Google and Facebook, New Media and Society, 20, 293-310.

Property Council of Australia (2018) Office Market Report. Available at https://www.propertycouncil.com.au/Web/EventsServices/ResearchData/Office Market Report Web/Events Services/Research Services/Office market report.aspx?hkey=7c43b696-cd314f6c-8314-4c62a4b0467a.

Talen, C. and Goldstein, N. (2015). Smart Offices: How Intelligent Building Solution are Changing the Occupant Experience, Intel-Sponsored White Paper, Navigant Consulting. Available at: https://info.switchautomation.com/hubfs/Switch_Content/Intel_sponsored_Navigant_White_Pa per.pdf.

Total Facilities (2017) Smart Building as Well and Good but How Sustainable Are They? June 21. Available at: https://totalfacilities.com.au/sustainability-and-energy-management/smartbuildings-well-good-sustainable/ 
Rice, J. (2010) Climate, carbon, and territory: greenhouse gas mitigation in Seattle, Washington, Annals of the Association of American Geographers, 100, 929-937.

Rocha, P., Siddiqui, A. and Stadler, M. (2015) Improving energy efficiency via smart building energy management systems: a comparison with policy measures. Energy and Buildings, 88, 203-213.

Rutherford, J. (2014). The vicissitudes of energy and climate policy in Stockholm: politics, materiality and transitions. Urban Studies 51, 1449-79.

Rutherford, J. (2018). Seeking effective infrastructures of decarbonisation in Paris. In A. Luque A, S. Marvin, H. Bulkeley (Eds.) Rethinking Urban Transitions: Politics in the Low Carbon City, New York: Routledge, 39-54.

Roberts, I. and Edwards, P. (2010). The Energy Glut: The Politics of Fatness in an Overheating World, London: Zed Books.

Rohracher, H. and Späth, P. (2013). The Interplay of Urban Energy Policy and Socio-technical Transitions: The Eco-cities of Graz and Freiburg in Retrospect. Urban Studies, 50, 1415-1431.

Ruparantha, R., Hewage, K., Sadiq, R. (2016) Improving the energy efficiency of the existing building stock: A critical review of commercial and institutional buildings, Renewable and Sustainable Energy Reviews, 53, 1032-45.

Santos, D. and Lane, R. (2017) A material lens on socio-technical transitions: the case of steel in Australian buildings. Geoforum, 82, 40-50.

Strengers, Y. (2013). Smart Energy Technologies in Everyday Life. Smart Utopias? Palgrave MacMillan.

Thomas, L., Rickwood, R. and Dilevska, J. (2015). The carbon cost of work-Impacts of office building and commuting energy in Sydney workplaces. Urban Policy and Research, 37, 238-58.

Warren, B., Christoff, P., and Green, D. (2016) Australia's sustainable energy transition: The disjointed politics of decarbonisation. Environmental Innovation and Societal Transitions, 21, 112.

Webb, J., Hawkey, D. and Tingey, M. (2016). Governing Cities for sustainable energy: The UK case. Cities, 54, 28-35. 


\begin{tabular}{|l|l|l|}
\hline \multicolumn{2}{|l|}{ Program Name } & Description \\
\hline Mandatory & $\begin{array}{l}\text { NABERS } \\
\text { Disclosure (Building Energy } \\
\text { Efficiency Disclosure Act) } \\
\text { National Construction Code }\end{array}$ & $\begin{array}{l}\text { Environmental performance rating scheme for commercial space. } \\
\text { Building Energy Efficiency Certificate (BEEC) for commercial office } \\
\text { spaces above 1000m2 when offered for sale or lease. } \\
\text { Regulates construction by state and territory governments. } \\
\text { Section J pertains to minimum energy efficient measures. }\end{array}$ \\
\hline Voluntary & $\begin{array}{l}\text { Green lease } \\
\text { GCA Green star }\end{array}$ & $\begin{array}{l}\text { Leases requiring owners to meet agreed energy efficiency } \\
\text { standards. } \\
\text { Green Building Council of Australia's environmental rating scheme. }\end{array}$ \\
\hline $\begin{array}{l}\text { Getter Buildings Partnership } \\
\text { Environmental Upgrade }\end{array}$ & $\begin{array}{l}\text { Agreement } \\
\text { Provides environmental audits of commercial spaces and offers } \\
\text { information, expertise and networking on how to improve NABERS } \\
\text { rating. } \\
\text { institutions. Aims to reduce barriers to sustainability and resource } \\
\text { use in commercial buildings to improve environmental } \\
\text { performance. } \\
\text { Finance agreements for small business and commercial buildings to } \\
\text { improve environmental performance. Facilitated through local } \\
\text { government, with loans repaid through council rates charges. }\end{array}$ \\
\hline
\end{tabular}

Table 1: Governance mechanisms orchestrating commercial building energy performance 


\begin{tabular}{|c|c|c|}
\hline Company & Monitoring and Analytics Features & Energy Management Capacities \\
\hline Bueno & $\begin{array}{l}\text { Data capture, monitoring and analytics } \\
\text { platform } \\
\text { Fault detection } \\
\text { Work tracking system }\end{array}$ & $\begin{array}{l}\text { Analytics-managed service on BMS, sub-metres and utility metres to achieve energy efficiency and } \\
\text { maintenance effectiveness } \\
\text { Predictive maintenance regime remotely monitors a building's BMS and building systems, and is } \\
\text { supported by engineers that triage anything revealed by the data before alerting the building } \\
\text { manager and contractors } \\
\text { High level tuning strategy optimisation available via engineers }\end{array}$ \\
\hline Envizi & $\begin{array}{l}\text { Data capture, monitoring and analytics } \\
\text { Fault detection and alarm }\end{array}$ & $\begin{array}{l}\text { Virtual energy meter that monitors, alarms and detects faults } \\
\text { Interval Meter Monitoring: monitor energy use and alert in case of anomaly } \\
\text { Identify track and eliminate energy waste }\end{array}$ \\
\hline Widesky & $\begin{array}{l}\text { Software-as-a-service } \\
\text { Data capture, storage and streaming } \\
\text { data analytics } \\
\text { Learning algorithms } \\
\text { Forecasting functions }\end{array}$ & $\begin{array}{l}\text { Precinct-level building data management } \\
\text { Visual energy displays (including cost and GHG emissions) } \\
\text { Energy metering } \\
\text { Real-time building control }\end{array}$ \\
\hline$E P \& T$ & $\begin{array}{l}\text { Data capture and monitoring via loT } \\
\text { sensors } \\
\text { Cloud based monitoring reporting } \\
\text { Data analytics } \\
\text { Al and Machine Learning }\end{array}$ & $\begin{array}{l}\text { Automated monitor energy use to pinpoint operational anomalies } \\
\text { Real-time detection of energy and cost-saving opportunities } \\
\text { Auditable to reporting standards of Carbon Disclosure Project, Dow Jones Sustainability Index }\end{array}$ \\
\hline Switch & $\begin{array}{l}\text { Software-as-a service } \\
\text { Smart, real-time building platform for } \\
\text { buildings and building portfolio } \\
\text { Cloud-based automated building } \\
\text { control } \\
\text { Fault detection and diagnostics }\end{array}$ & $\begin{array}{l}\text { Automated importation of data from BMS, equipment, metres, sensors, utility bills, live weather } \\
\text { feeds for cloud-based analytics } \\
\text { Granular visibility of building performance in real-time to enable remote triage, diagnosis and } \\
\text { resolution } \\
\text { Custom dashboards for performance reporting; } \\
\text { Remote control of systems to improve performance. } \\
\text { Central monitoring and control buildings and systems, down to individual devices and equipment }\end{array}$ \\
\hline Buildings Alive & $\begin{array}{l}\text { Data capture and monitoring } \\
\text { Daily customized user feedback } \\
\text { Predictive alerts } \\
\text { Community of Practice network }\end{array}$ & $\begin{array}{l}\text { Tracking patterns of energy and resource use } \\
\text { Timely feedback to building operators } \\
\text { Alerts on upcoming weather conditions to enable pre-emptive FM action } \\
\text { Integrates utilities data, live weather feeds for data analytics }\end{array}$ \\
\hline Skyspark & Software-as-a-service & $\begin{array}{l}\text { Automatic identification of patterns, faults and anomalies to "find what matters" via "actionable } \\
\text { intelligence" }\end{array}$ \\
\hline
\end{tabular}




\begin{tabular}{|l|l|l|}
\hline & $\begin{array}{l}\text { Data capture and algorithm-driven } \\
\text { analytics } \\
\text { Fault detection } \\
\text { View Builder function to generate } \\
\text { reports }\end{array}$ & $\begin{array}{l}\text { Live links to building automation systems and smart metres and smart devices } \\
\text { Manage real-time data portfolios } \\
\text { Visualisation of energy data } \\
\text { Build customisation reports }\end{array}$ \\
\hline Kinesis & $\begin{array}{l}\text { Data analytics } \\
\text { Automated data capture and alerting } \\
\text { Automated customized and fixed } \\
\text { reporting }\end{array}$ & $\begin{array}{l}\text { Corporate sustainability reporting platform } \\
\text { Automated data capture across utilities, BMS, third party suppliers, metres, and qualitative data } \\
\text { Real time performance management and building optimisation } \\
\text { Organisational and asset-level dashboards } \\
\text { One touch reporting, templated to mandated and commonly used reporting obligations } \\
\text { Provides technology plus with unlimited access to data analysts and sustainability consultants }\end{array}$ \\
\hline Coppertree & $\begin{array}{l}\text { Software-as-a-service } \\
\text { Cloud-based data monitoring and } \\
\text { analytics }\end{array}$ & $\begin{array}{l}\text { Harvests data from building management and automation systems for cloud-based analytics } \\
\text { Customisable dashboards } \\
\text { Provide data reports and actionable insights for building energy optimisation } \\
\text { Enables fine-turning every for optimal energy efficiency every few seconds }\end{array}$ \\
\hline Building IQ & $\begin{array}{l}\text { Software-as-a-service } \\
\text { Data capture and monitoring } \\
\text { Real-time user input } \\
\text { Cloud-based data analytics } \\
\text { Fault detection } \\
\text { Predictive maintenance } \\
\text { Learning algorithms }\end{array}$ & $\begin{array}{l}\text { Predictive energy optimisation } \\
\text { Automated building control to optimize performance }\end{array}$ \\
\hline
\end{tabular}

Table 2 Indicative summary of Building Energy Management Platform/Data Analytics firms operating in Sydney 
